\title{
A designer's view: The perspective of form and function
}

\author{
Dirk Jan Boerwinkel, Arend Jan Waarlo and Kerst Boersma \\ Freudenthal Institute for Science and Mathematics Education, Utrecht University, The Netherlands
}

\begin{abstract}
Perspectives are domain-specific strategies employed by experts in a specific field to formulate and investigate questions. Such strategies may therefore serve as good models for acquiring knowledge. Based on this premise, we developed the perspective of form and function, as used by both biologists and technical designers, into a tool for constructing knowledge in primary science education. Firstly, we developed a model of the perspective of form and function. It proved possible to make one model for both biological and technical practice. In order to ascertain whether primary school students could acquire the perspective of form and function, the model of the perspective of form and function was then developed into a learning tool dubbed the 'designer's glasses'. During lessons, the students (aged 11) learned to use the tool to translate from function to form and vice versa, for both technical and biological phenomena. The 'designer's glasses' helped the students to analyse and compare technical and biological designs and increased their observational skills and understanding of design. However, specific coaching by the teacher was needed to achieve the necessary steps in observation and discussion.

Key words: Form and function, design, domain-specific strategy, perspective
\end{abstract}

\section{Introduction}

An important goal of primary science education is for students to be stimulated to investigate their environment and formulate their own questions. But stimulation alone is not enough. Science education should also improve and expand observational skills and the structuring of experiences. We suggest that students should be taught to use different specific strategies to investigate their environment.

In this research, the explicit use of perspectives is proposed as a learning strategy in science teaching. Perspectives are defined as domain-specific thinking and working strategies which experts use in their field. Perspectives include the questions experts ask, as well as the heuristics that they use to answer them. By teaching perspectives as a learning strategy, students could learn which types of questions are more fruitful in generating knowledge in the study of phenomena, and also learn specific heuristics for finding answers to these questions.

Perspectives in biology include those of form and function, and of unity and diversity. For example, in the study of a leaf, a form-and-function perspective leads to questions and observations about the function of folding, as illustrated in Figure 1, whereas a unity-and-diversity perspective leads to questions and observations about differences between related species.

In this research, we selected the perspective of form and function to investigate the possibility of using perspectives as a learning strategy (Boerwinkel, 2003). The research question was formulated as follows:
- How can primary school students acquire the perspective ofform and function as a learning strategy? In order to answer this question, two other questions had to be answered first:

- What is the content and structure of the perspective of form and function?

- How can an expert perspective be translated into a learning tool for primary science education?

Based on the answers to these two questions, a Learning and Teaching Strategy was designed. We hypothesised that: the Learning and Teaching Strategy is effective for acquiring the perspective of form and function.

\section{Theoretical background}

The concept of perspectives as learning strategies is based on the idea that these strategies indicate ways to generate new knowledge. Perspectives are also called 'guiding principles of enquiry' (Schwab, 1963) or 'epistemic games' (Collins and Ferguson, 1993; Perkins, 1997). Under somewhat different titles, comparable biological perspectives have been mentioned by other researchers (Schwab, 1963; National Research Council, 1996; Janssen, 2000).

Perspectives provide suggestions for the kind of questions that can be asked and for the strategies to investigate them. In this research, domain-specific learning and teaching tools are also called perspectives. In this paper therefore, the term 'perspective' has two meanings: it means both a domain-specific thinking and working strategy which experts use in their field of practice, and a domainspecific strategy that can be used in learning and teaching. 
Learning to use perspectives as methods for knowledge construction is in line with the constructivist view on learning, namely that the student constructs knowledge based on pre-existing knowledge. The explicit emphasis that perspectives offer on the way in which knowledge is constructed is based on the cultural historical view on learning, which holds that the role of the teacher is to teach how to construct knowledge (van Oers, 1995). Both social constructivism and the cultural historical view emphasise the importance of a shared construction of knowledge, in which the student enters into dialogue with peers and with the teacher. Both student and teacher have to verbalise their thoughts and actions to make communication about them possible. These conditions, that teachers and students should explain their thoughts and reflect on the way they generate knowledge, are best met by the cognitive apprenticeship approach (Collins et $a l, 1989)$. In this approach, the teacher demonstrates the activity while thinking aloud. The students then practise the activity while the guidance by the teacher gradually fades.

Perspectives should be applicable to different situations. In other words, transfer is very important. Theories on transfer show that perspectives can best be acquired in a realistic context (Simons and Verschaffel, 1992). By applying them to other contexts, the perspective becomes more explicit as a cognitive tool. Furthermore, the student should be encouraged to reflect regularly on his/her actions in order to acquire the perspective as a learning strategy. This is another reason why it is important that students should put their thoughts and actions into words.

Literature on the learning of complex skills suggests that a small nucleus of content should be used. This nucleus should contain the main relationships and concepts in a schematic form, and can act as a growing 'germ cell' during the learning process (Engestrom and Hedegaard, 1984; Reigeluth, 1987).

Based on these theories, criteria for a Learning and Teaching Strategy (LTS) can be formulated as follows.

The LTS should:

- invite students and teachers to verbalise their thoughts

- invite students to reflect on the way they generate knowledge

- include different realistic contexts and stimulate transfer amongst them

- include a small and recognisable nucleus of content that can be used as a growing representation of the perspective.

\section{Design of the study}

The first step of the research was to analyse how the perspective of form and function is used in formulating research questions, both in biological research and in technical design, and then to analyse which heuristics are generated by this perspective. This analysis was carried out by studying literature about the historical development of biological research and about design procedures. A model of the perspective of form and function was

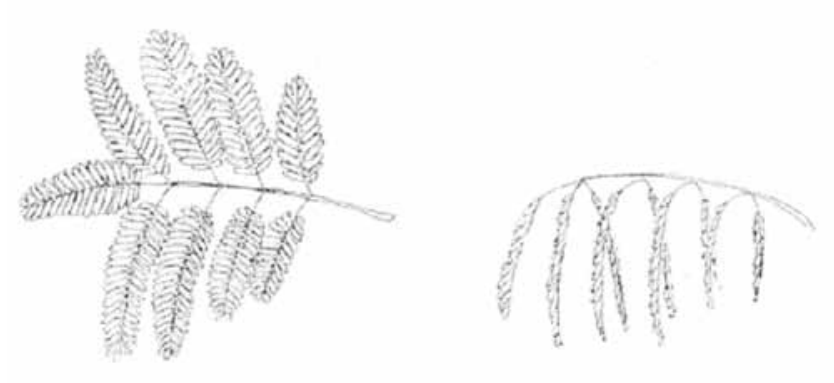

Figure 1. Folding leaf of Caesalpinia coriaria.

developed in which the different questions and heuristic strategies could be placed.

In the second part of the research this model was translated into learning goals and learning strategies for primary science education. A scheme based on the perspective of form and function was developed as a learning tool. The role of the scheme was to function as a 'germ cell' in which both observations and questions could be placed.

A learning and teaching strategy was then designed based on these goals, the 'germ cell' scheme and the criteria mentioned above. In this type of research developmental research (Lijnse, 1995) - the learning and teaching strategy acts as an hypothesis about the learning of the students. To test this hypothesis, a scenario which predicts student learning is written, and tested to see whether the scenario brings about the predicted results in school practice. Based on the Cognitive Apprenticeship approach, the students gradually learnt to work more independently with the perspective, by first observing how their teacher used it, then by answering specific questions which were derived from the heuristics and, thirdly, by accomplishing the final design process without help.

Data gathering methods included observation, as well as analysis of worksheets, questionnaires and interviews conducted with small groups. Based on the learning goals, predicted student activities were specified, for example 'student weighs advantages and disadvantages of alternative designs' or 'student uses analogies'. Protocols of observed lessons and worksheets were scored according to the presence of these elements.

Three classes of, on average, 25 children aged about 11 years participated in this study.

\section{Towards a model for the perspective of form and function}

Function, form, systems and design

In this research, both organisms and technical objects are viewed as systems. In many cases systems have interacting subsystems that interact with other systems to form a suprasystem (von Bertalanffy, 1968). The function of a system can be described as its role in the capacity (scope) of the suprasystem. For example: the function of the valves in the heart is to prevent the blood from flowing back and so contributes to the capacity of the heart (the suprasystem) which is pumping blood through the body. This functional aspect, which is called the causal 
role (Wouters, 1999), applies to both technical and biological systems. However, biologists are also interested in the survival value, another aspect of function. This requires another kind of explanation, in which the effect and conditions that contribute to survival are analysed. Wouters calls these 'design-explanations'. In many cases, functional explanations contain both a causal role and survival value.

We categorised four main functions derived from Von Uexküll's 'Funktionskreise' (Von Uexküll, 1928), namely:

- providing food (providing cells with fuel and oxygen, building materials and water)

- protection against enemies

- protection against the physical environment

- reproduction.

In technical design there is a parallel to the concept of value. In addition to its role in a suprasystem, a technical object also has a value. People buy and produce things because they contribute to values like safety, pleasure and comfort. This means that values also dictate which functions are important. Just as in biology a function can always be linked with survival value, functions in technical objects can always be linked to values (Cross, 1989; Roozenburg and Eekels, 1991).

Form is defined as the material, spatial and temporal properties of a feature. A feature can be either a structure or a process, on any level of the system. Form-descriptions of features in biology include, for example, the spatial form of an enzyme, the material properties of a feather, and the pattern of a bird's song. Examples of form-descriptions in technical design include, for example, the spatial form of a valve, the material properties of a chip, and the frequency of an emitter.

Questions about function can be about structures as well as about processes. That is why we speak of formfunction instead of structure-function. In this aspect our approach differs from the Structure-Behaviour-Function model by Hmelo-Silver and others (Hmelo-Silver, Marathe and Liu, 2007). In their model, behaviour is the link between structure and function. In our model, behaviour can also have form, and does not directly explain the function of a structure. Birdsong is an example of a behaviour whose form (rhythm, duration, volume, etc) can also be described in relation to the function. For this reason, we chose to use the term 'feature' for both structures and processes that have a form.

The use of the word 'design' needs special explanation. In biological research it has heuristic value to consider organisms as 'good designs'. The use of intentional language in these cases means that organisms and parts of them are viewed as if they were designed (Dennett, 1987). After a design has been selected, it can undergo changes because it is often used in a different way from that for which it was selected. A screwdriver can be used to open cans. Birds' feathers, probably originally selected for the regulation of body temperature, evolved for flying. In other words, design specifications other than those originally intended can evolve in both living and technical designs (Gould and Vrba, 1982; Petroski, 1993).
Research questions within the perspective of form and function

Based on the analysis of literature on biological research and technical design, a description is made of the kind of research within the perspective of form and function.

The kind of research questions which arise from the perspective of form and function depend on whether form, function or both are known.

Four main research questions can be distinguished:

I. What can be the function Y of feature X?

II. What feature X can fulfil function Y?

III. How does form X bring about function Y?

$I V$. Why has feature X form A and not A'?

In Question I, the form of a feature is known, but the function is unknown.

An example in biology of this kind of question is Tinbergen's research on the behaviour of the herring gull, in which the feature (removing eggshells from the nest by parent birds) was known, but the function unknown (Tinbergen, 1963).

In Question II, the function is known, but the feature that is responsible for this function is unknown. An example is the search, prior to 1950, for the molecular base of heredity when it was clear that there was a structure somewhere in the cell that carried genetic information. The question was, however, which molecule was the carrier (Schroedinger, 1944).

To address question II, a new feature and form has to be designed in technical design, whereas in biological research the existing feature and form must be found.

In Question III and IV, both the form of the feature and the function are known. Question III is a 'how' question in which the mechanism by which form $\mathrm{X}$ performs function Y is studied. An example of Question III is the search for the genetic code: DNA proves to be the carrier of genetic information. How is this information coded in DNA?

Questions of type IV arise when a known feature seems to be inexplicably complex, energy-consuming or dangerous. The question is then why this feature is used and not a plausible alternative (a 'counterfactual', Wouters, 1999). In technical design, the search for a better design is indicated. In this kind of research, the fact that every design is a compromise between contradictory demands is important in both biological and technical research.

\section{The basal model of the perspective}

In the perspective of form and function, two kinds of relationships appear to connect form with function:

1. A causal relationship that describes and explains the effects of form on function.

2. A design route that directs the process of finding a suitable form through design-specifications that can be derived from the function.

Route 1 (termed the 'high road') normally leads to one function.

Route 2 (termed the 'low road') is, however, an heuristic route that limits the search but can in principle lead to 
many different forms. Schroedinger used this route in his search for the molecule responsible for carrying genetic information. He used design specifications derived from the function and concluded that this molecule must be an aperiodic crystal: aperiodic because a periodic molecule could not contain information, and a crystal because it needed to have sufficient stability to fulfil the task of preserving genetic information (Schroedinger, 1944).

These routes can be summarised in the basal model of the perspective of form and function (Figure 2).

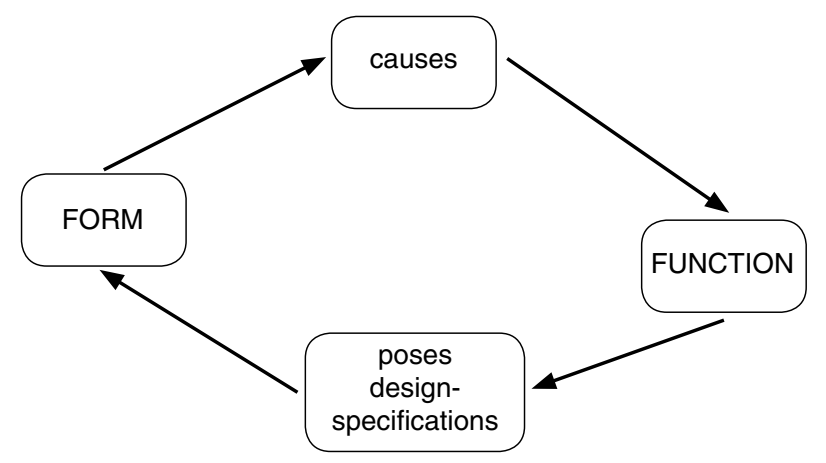

Figure 2. Basal model of the perspective of form and function.

The common model of the perspective of form and function

As we see in these examples, heuristics within the perspective of form and function can start both at the level of form and of function, and go in both directions over the 'high road' or the 'low road' of the basal model. That is why this way of reasoning is termed 'hither-and-thitherthinking'.

In the common model of the perspective of form and function (Figure 3), both roads between form and function are present, but are elaborated.

1. A form causes a function via an effect under certain conditions. For example: the folding of a leaf (form) in dry circumstances (conditions) reduces the exposed surface area (effect) and so contributes to protection against water loss (function).

2. Design specifications can be derived from a function and guide the search for a fitting form. Apart from the function, the environment and limiting conditions such as the available energy and the design of connected subsystems influence design specifications.

3. Functions are coupled with a value, e.g. in biological systems certain functions have a survival value.

4. Analogies are important heuristics in both biological research and technical design.

\section{The development of the scenario}

A central part of the learning and teaching strategy (LTS) to acquire the perspective of form and function is the development of a 'germ cell' that represents the perspective and structures the learning experiences. This germ cell, dubbed the 'designer's glasses' is a scheme in which the student writes down his observations and thoughts, and so gradually elaborates the perspective of form and function. The scheme (Figure 4) was derived from the model previously described:

- The form of the feature is described in the left-hand box, the function is described in the right-hand box.

- The relationships between form and function are described in the middle box, via both the 'high' and 'low roads'.

- Heuristics in the form of questions can be added to all three parts.

- Furthermore, the analogy with glasses is fitting as the scheme, taken as a whole, looks like a pair of spectacles and thus represents a perspective, or a way of observing reality. To carry the analogy further, different kinds of 'glasses' enable one to see other aspects of reality.

The learning goals of the learning and teaching strategy and the four question types can be placed in the tool as shown in Figure 5.

Goals 3 and 4 describe the 'hither-and-thither thinking' that is characteristic of the perspective of form and function, and are linked with the questions and heuristics

Figure 3. The common model of the perspective of form and function.

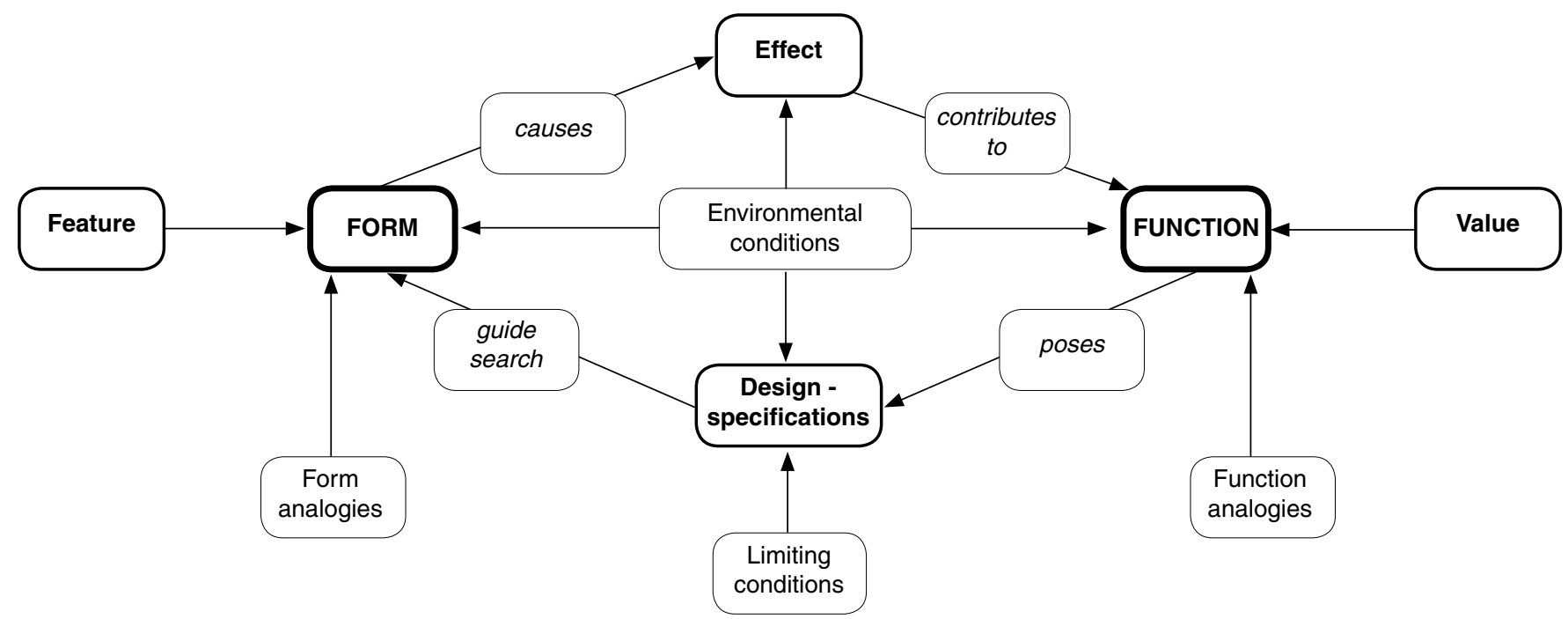


The designer's glasses

\begin{tabular}{|l|l|l|}
\hline What does it look like? & Why thus and not otherwise? & What is the function? \\
\hline & & \\
& & \\
\end{tabular}

Figure 4. The scheme of the 'designer's glasses'.

described earlier. In order to use the perspective consciously, the student not only has to demonstrate the different actions, but must also be able to apply the hitherand-thither-thinking in different contexts, as well as explain his thoughts and actions to others.

The transfer criterion of the LTS is met by using the perspective of form and function both in technical design and in studying biological objects. The LTS is elaborated on in a scenario comprising 12 activities, of which the first half concern the study of technical designs, and the second half the study of biological phenomena. At the end of both the first and second halves of the LTS, a questionnaire invites students to reflect on the perspective of form and function.

The technical component starts with a design-activity, comprising a type II question, namely from function to form. During the presentation of the designs, the students explain and comment on their designs. Type III and IV questions play a role during these presentations. Secondly, students study objects, discriminating between parts and questioning their functions (type I question). During these activities, type III and IV questions will also emerge, which should lead via hither-and-thither-thinking to new observations and new questions.

The biological component starts with the analysis of biological phenomena in the same way as the students analysed the technical objects (type I, III and IV questions). The four main functions for survival - providing food, protection against enemies, protection against the physical environment and reproduction - are then introduced. Finally, starting with these functions, students are

Figure 5. The framing of learning goals in the scheme.

\section{The designer's glasses}

\begin{tabular}{|c|c|c|}
\hline What does it look like? & Why thus and not otherwise? & What is the function? \\
\hline $\begin{array}{l}\text { Goal } 1 \\
\text { Describe organisms } \\
\text { and artefacts as a } \\
\text { whole and as related } \\
\text { parts. } \\
\text { Goal } 2 \\
\text { Describe the form } \\
\text { of structures and } \\
\text { processes. }\end{array}$ & $\begin{array}{l}\text { Goal } 3 \\
\text { Relate form with function and } \\
\text { vice versa. } \\
\text { I. What can be the function } Y \text { of } \\
\text { feature } X \text { ? } \\
\text { II. What feature } X \text { can fulfil } \\
\text { function Y? } \\
\text { Goal } 4 \\
\text { Explain relationships between } \\
\text { form and function. } \\
\text { III. How does form } X \text { bring about } \\
\text { function } Y \text { ? } \\
\text { IV. Why does feature } X \text { have form } \\
\text { A and not A'? }\end{array}$ & $\begin{array}{l}\text { Goal } 5 \\
\text { Describe functions as } \\
\text { contributions to the } \\
\text { functioning of a higher } \\
\text { system. }\end{array}$ \\
\hline
\end{tabular}

asked to design an animal that can survive in given environmental conditions (type II question). Type III and IV questions once again play a role during the presentation of, and commentary by, the students.

\section{Results in the classroom \\ Data analysis}

In order to analyse the data from discussions and worksheets, a system of categorisation was developed, based on the scheme of the designer's glasses and the learning goals presented in Figure 5. The main categories are listed in Table 1.

Examples of question and worksheet analyses are presented below.

\section{Thinking in parts and the whole}

The biological objects used in this study were: brow and eyelid, germinating beans, bird song, seeds and skulls. The technical objects that were observed included paperclips and clothes pegs, as well as objects in the classroom that the students selected. The results showed that children have difficulty distinguishing the functions of parts from the functions of the whole for both biological and technical objects.

Students often overlooked parts, especially when they could not perceive a function for them. Examples of this phenomenon were:

Example 1. Students studying germinating beans did not describe the clearly visible endocarp until the teacher discussed its function. Then they were able to mention many different functions, such as protection against mould or prevention of germination while still on the plant.

Example 2. When studying a wooden ruler, students did not describe the metal lining until its possible function was discussed.

Specific coaching was needed to describe functions. To this end, questions that mediate between form and function were found to be helpful, for example:

'What would happen if this part was absent?'

\section{'Would it make a difference if this form/} material was $X$ instead of $Y$ ?'

Although these questions were present on the 'designers glasses', teacher assistance proved necessary as certain parts were not noticed at all.

\section{Discourse about design}

Students were well able to discuss their own technical or biological designs and use questions and arguments both from form to function and from function to form.

Example 1. The students were given the task of designing a solution to the problem of pencils falling off the school benches. One group designed a metal thread over the bench with the pencil connected to this thread with a string.

Question by student: Why is the thread 
Table 1. Categories used in the analysis of discussions and worksheets

1.1 Identify parts of a feature
1.2 Indicate the whole of which the feature is the part
2.1 Describe the form of a structure (e.g. spatial form, material,
construction)
2.2 Describe the form of a process (e.g. birdsong, germination)
3.1.a Pose the question about the function of a feature (Question Type I)
3.1.b Indicate the function of a feature
3.2.a Pose the question about the feature for a given function (Question
Type II)
3.2.b Indicate the feature that has a given function
3.2.C Design a feature with a given function
4.1.a Pose the question on how a feature works to fulfil its function
(Question Type III)
4.1.b Explain how a feature works
4.2.a Pose the question why feature A is selected instead of A'
(Question Type IV)
4.2.b Weigh advantages and disadvantages of features
5.1 Relate functions of parts to functions at higher levels
5.2 Make design specifications

over the bench made of metal and not of rope? (cat.4.2.a)

Answer by student: This way the strings can slide over the metal thread and reach the whole bench (cat.4.1.b)

Example 2. The students were given the task of designing an animal that would survive in a given environment. They then analysed the designs, raising questions and remarks such as:

\section{How does your animal survive the dry period? (cat.3.2.a)}

\section{What is the function of this part? (cat.3.1.a)}

\section{If you defend the eggs with bad smells they will be easier to find. (cat.4.2.b)}

With some coaching, the students understood design 'trade-off' in both technical design and biological phenomena. Examples include:

Example 1. When discussing whether ash seeds (Fraxinus excelsior) have a better design than horse chestnut seeds (Aesculus hippocastanum), the students answered that horse chestnut and ash have the same chance of survival because although many of the ash seeds will not survive, there are a lot more of them.

Example 2. The teacher cut off a section of the arms of a clothes peg and asked whether it would still work. The students noted that they would be harder to compress, so short arms are not an advantage. The teacher then asked why the arms were not made much longer so that the clothes peg would be easier to compress. The students responded that long arms would make the peg heavier, more difficult to handle, and top heavy causing it to topple over. They therefore realised that there is an optimum length.

The four functions necessary for survival were used in the designs. The assignment was to design an animal that fed on roots, was threatened by snakes and bears and could survive in an environment with hot summers and cold winters. The students again realised that a design can never be perfect for all functions, and that choosing a certain feature for one function may create a problem for another.

This was illustrated in the design created by two girls. The choice of long hollow nails for digging food made it impossible for the animal to run away to escape predators. The suggestion of a protective covering of scales posed problems for surviving hot summers. A possible solution to this was to open the scales in hot weather.

Plant functions posed more problems: children often express plant functions in terms of how they are used by humans or animals rather than for the survival of the plant itself. Even when studying germinating beans, only $9 \%$ of the students indicated reproduction as a function of the bean, with $76 \%$ of students mentioning food for people as the only function. The same trend was seen in an exercise in which students had to attribute functions to different phenomena such as flowers, spines, birdsong, stones and leaves. For example, leaves were mainly perceived as food for animals, with no function for the plants themselves.

Although students enjoyed discussing their own designs, they sometimes considered discussion about existing biological objects useless. To the question: why discuss something that cannot be improved anyway? A student remarked:

I don't think that you can look at a clothes peg in the same way that you look at a bean. A bean does not have tasks, it cannot be improved.

\section{Educational implications}

This research shows that studying the relation between form and function is a domain-specific mode of inquiry with strategies that can be used in investigations by students. Although this research is done in primary education, the explicit use of perspectives is probably most effective in teacher education. This can help teachers to ask questions from different perspectives and teach both about the subject as well as about biological methodology.

The principle of form and function however is often neglected in biological education. This research shows that there are many educational possibilities such as designing animals under given conditions posed by the four survival functions. By designing, students will realise that a biological design, like any other design, has to be a compromise between competing demands and that every organism can be seen as a different solution for coping with these survival functions. On lower levels of organisation, students should realise that the function of parts is not the same as the function of the whole, for example the function of an eyelid is not seeing but protection. In upper secondary education, form-function questions can very well be applied to molecular biology, 
especially to proteins. Molecular research includes many questions about protein function, structure and the relation between them.

Attention should be given to the use of the word design. For students in primary education it is often taken as self-evident that organisms are perfectly adapted. Older students might question whether talking about design implies a plan and a designing agent. It should be clear that the use of these terms helps to formulate research questions but does not describe the mechanism by which form and function are related.

\section{References}

Boerwinkel D J (2003) Het vormfunctieperspectief als leerdoel van natuuronderwijs: leren kijken door de ontwerpersbril. PhD thesis. Utrecht: CD- $\beta$ Press. http://igitur-archive.library.uu.nl/dissertations/2003-0910-085550/title.pdf

Collins A, Brown J S and Newman S E (1989) Cognitive apprenticeship: teaching the crafts of reading, writing, and mathematics. In: Resnick $\mathrm{LB}(\mathrm{Ed})$ Knowing, learning, and instruction: Essays in honor of Robert Glaser. (pp 453-494) Hillsdale: Lawrence Erlbaum Associates.

Collins A and Ferguson W (1993) Epistemic forms and epistemic games: structures and strategies to guide inquiry. Educational Psychologist, 28, 1, 25-42.

Cross N (1989) Engineering design methods. Chichester: John Wiley \& Sons Ltd.

Dennett D (1987) The Intentional Stance. Boston: MIT Press.

Engestrom $Y$ and Hedegaard M (1984) Teaching theoretical thinking in elementary school: The use of models in history/biology. In: Bol E, Haenen J P P and Wolters M A (Eds) Education for cognitive development. Proceedings of the Third International Symposium on Activity Theory. (pp 170-193) 's Gravenhage: SVO.

Gould S J and Lewontin R C (1979) The spandrels of San Marco and the Panglossian paradigm: a critique of the adaptionist programme. In: Maynard Smith $\mathrm{J}$ and Holliday R (Eds) The evolution of adaptation by natural selection. London: Royal Society of London.

Gould S J and Vrba E S (1982) Exaptation-a missing term in the science of form. Paleobiology, 8, 4-15.

Hmelo-Silver C, Marathe S and Liu L (2007) Fish Swim, Rocks Sit, and Lungs Breathe: Expert-Novice Understanding of Complex Systems.
Journal of the Learning Sciences, 16:3, 307-331.

Janssen F (2000) Biologie in perspectief. NVOX, 6, 283-286.

Lijnse P L (1995) 'Developmental research' as a way to empirically based 'didactical structure' of science. Science Education, 79, 189-199.

National Research Council (1996) National Science Education Standards. Washington: National Academic Press.

Perkins D N (1997) Epistemic games. International Journal of Educational Research, 27, 49-62.

Petroski $\mathrm{H}$ (1993) The evolution of useful things. London: Pavilion Books.

Reigeluth C (1987) Instructional theories in action: Lessons illustrating selected theories and models. Hillsdale, NJ: Erlbaum.

Roozenburg N F M and Eekels J (1991) Product ontwerpen, structuur en methoden. Utrecht: Lemma B.V.

Schroedinger E (1944) What is life? Cambridge: Cambridge University Press.

Schwab J J (Ed.) (1963) Biology teachers' handbook. New York: Wiley.

Simons P R J and Verschaffel L (1992) Transfer: Onderzoek en onderwijs. Tijdschrift voor Onderwijsresearch, 17, 3-16.

Tinbergen N (1963) On aims and methods of ethology. Zeitschrift für Tierpsychologie, 20, 410-433.

Van Oers H J M (1995) Cultuuroverdracht als reconstruerende activiteit. Pedagogisch Tijdschrift, 20, 263-275.

Von Bertalanffy L (1968) General system theory. New York: George Braziller.

Von Uexküll J (1928) Theoretische Biologie. Berlin: Springer.

Wouters A (1999) Explanation without a cause. Verklaren zonder oorzaken te geven. Utrecht: Zeno.

Dirk Jan Boerwinkel (corresponding autbor) is researcher in biology education at the Freudenthal Institute for science and matbematics education, Utrecht University, the Netherlands. Email:D.J.Boerwinkel@uu.nl. Arend Jan Waarlo is senior lecturer in biology education and bolds a special chair in Genetics \& bealth communication. Kerst Boersma is bonorary professor in biology education.

\section{Calling all Schools and Colleges...}

It's not easy to stay up-to-date. Both biology and educational research are rapidly developing fields. Time is precious - making it important to read the right journals. Now you can provide all your biology teachers with their essential reading in one move.

\section{Journal of Biological Education}

The Journal of Biological Education brings you the latest developments in biology education - accompanied by straight-forward, practical applications and accessible reviews. JBE is fully peer-reviewed and includes educationa theory, pedagogical research, reviews, practical biology-related exercises, and news items. Results can be easily understood and applied in the classroom.

\section{Biologist}

Biologist carries the full richness and diversity that is biological research today. Science is brought to life with stimulating and authoritative review articles while topical pieces discuss science policy, new developments or controversial issues. Biologist is fully peer-reviewed and citation-listed; it is also colourful, well-written and packed with fascinating details from all the life sciences - making it ideal for educators at all levels.

Join the scheme today..

...and you will immediately start to receive Biologist, with four issues per year, and the JBE, with four issues per year. In addition, you will be entitled to discounts on other Society publications, such as Biological Nomenclature and the Studies in Biology book series. Add to this access to the Society's educational support and you have a package that's not to be missed.

UK school rate - £80.00 Overseas School rate - £110.00 
Copyright of Journal of Biological Education is the property of Institute of Biology and its content may not be copied or emailed to multiple sites or posted to a listserv without the copyright holder's express written permission. However, users may print, download, or email articles for individual use. 